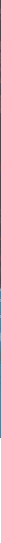

\title{
Are education and skills being distributed more inclusively?
}

- Between 2000 and 2013 the share of 25-64 year-olds with tertiary education grew by $3.1 \%$ a year on average across OECD countries, while the share of those without an upper secondary education fell by $2.9 \%$.

- In 2013 , more than $40 \%$ of adults still lacked an upper secondary education in five OECD countries.

- Some countries increased their tertiary attainment rates faster than they reduced lower educational attainment rates, while others (Poland, Luxembourg, Czech and Slovak Republics, and Korea) realised similar tertiary attainment increases but also reduced their below upper secondary attainment rates by the same amount.

- In all countries the share of low-skilled adults is lower among younger age groups than among older ones, but in some countries more than $20 \%$ of adults still have low literacy skills.

- In all countries the distribution of literacy skills is skewed towards the bottom, with a greater spread between the median and the bottom $10 \%$ than between the median and the top $10 \%$.

Educational opportunities have a very important impact on a person's life. Employment, earnings, well-being, health and trust are all strongly related to education and skills. A lack of high-quality educational opportunities is the most important way in which poverty, social inequality and exclusion are transmitted from one generation to another. For countries to grow and progress in a sustainable way, educational opportunities should be distributed in an inclusive way.

The inclusiveness of educational systems can be assessed in two ways: first, by looking at the share of people with low educational attainment or low skills and second, by looking at the size of the differences in attainment levels and skills distributions. This briefing examines both measures, and tracks their evolution over time.

The share of those with low education is decreasing rapidly, but not at the same rate in all countries. Most analyses of educational attainment rates look at the increases in the share of people with tertiary education, and over the past decades OECD countries have witnessed a remarkable growth of such highly educated people. Among OECD countries with data for all years between 2000 and 2013, the number of people with tertiary education grew by $3.1 \%$ on average per year.

But what has happened at the bottom of the educational ladder? Did educational expansion also decrease the share of people with low levels of education in the population? Figure 1 shows that over the same period, the share of 25-64 year-olds without an upper secondary education decreased by 2.9\% per year on average across OECD countries with data for all years, slightly slower than the growth rate for tertiary attainment, but many countries reduced low educational attainment rates much faster. The highest reduction rates can be found among countries that had reduced the share of people without an upper secondary education to below the OECD average of $24 \%$ in 2013. Unfortunately, in five countries, more than $40 \%$ of the population still have low educational attainment, and those countries have not even reached the average reduction rate of $2.9 \%$ per year. 
Figure 1. Share of 25-64 year-olds with below upper secondary education, and average annual rate of reduction (2013)

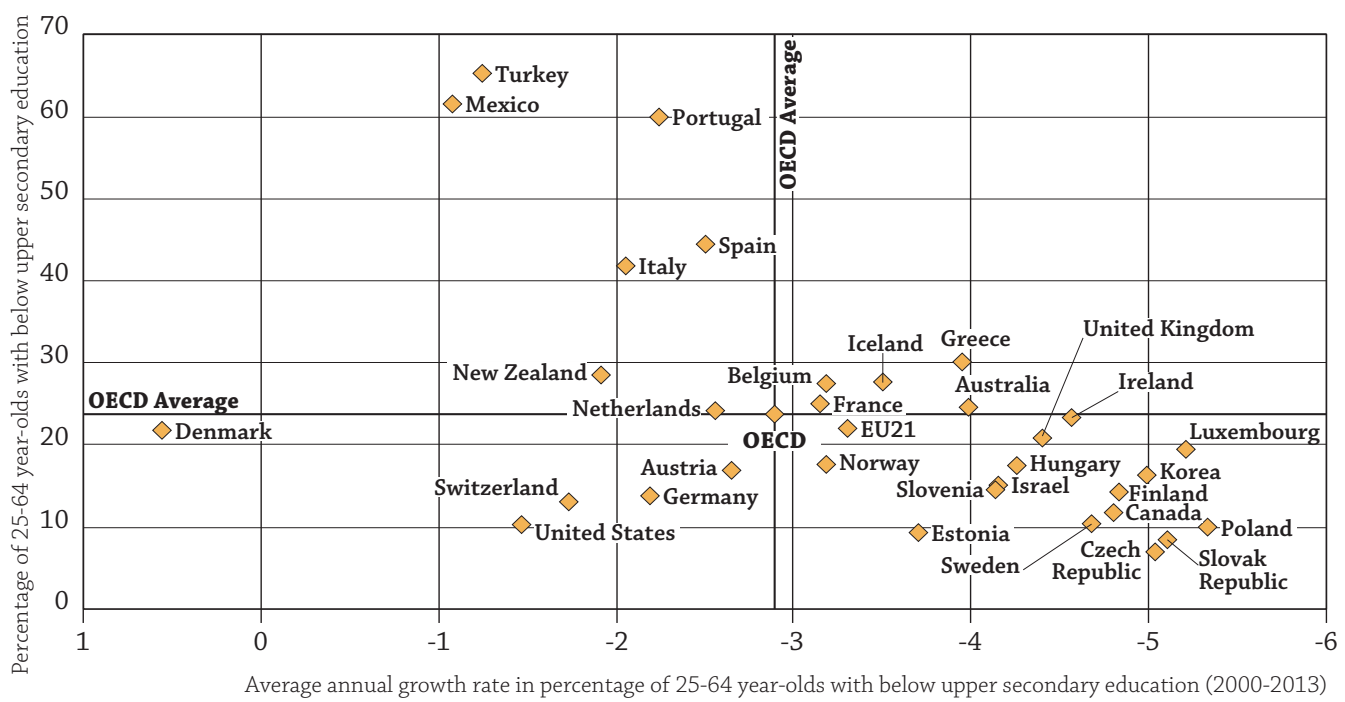

Sources: OECD Online Education database, www.oecd.org/education/database.htm; OECD (2014), Education at a Glance 2014: OECD Indicators, http://dx.doi.org/10.1787/eag-2014-en.

In some countries, educational attainment growth at the top has come at the expense of the bottom. Figure 2 shows the average annual change in below upper secondary and tertiary attainment rates, and the difference between them, for the period 2000-2013. Countries exhibit very different patterns of educational expansion. To the left we find countries such as Sweden, Finland, Israel and Canada, which have seen rates of low educational attainment falling faster than tertiary attainment rates have risen; to the right countries such as Portugal, Turkey, Denmark, Italy and Switzerland,

Figure 2. Average annual growth rates in below upper secondary and tertiary education (2013)

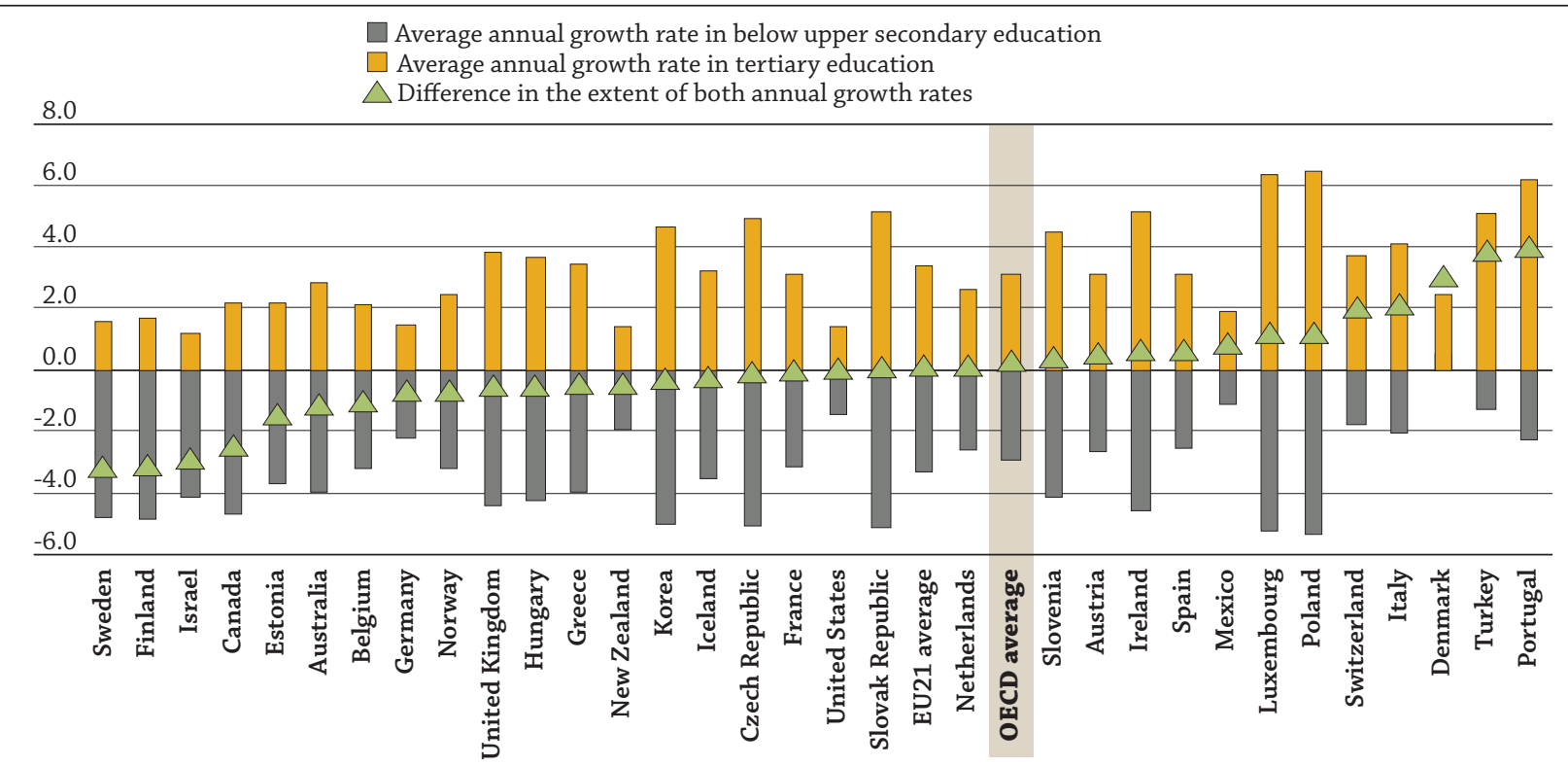

Note: Countries are ranked in increasing order of the difference between tertiary and below upper secondary attainment growth rates.

Sources: OECD Online Education database, www.oecd.org/education/database.htm; OECD (2014), Education at a Glance 2014: OECD Indicators, http://dx.doi.org/10.1787/eag-2014-en. 
where tertiary attainment has grown faster than low attainment has fallen. Some countries have low annual rates of change; others have gone through a much more rapid expansion in educational attainment. Compare for example the cases of Turkey and Korea: both share a similar annual growth rate in tertiary attainment, but in Korea this has been accompanied by a similar or even slightly higher fall in low education attainment rates, while in Turkey the share of 25-64 year-olds without an upper secondary education diminished only slightly.

The share of adults with low literacy skills is also decreasing, but in some countries it remains at a high level. Moving from educational attainment to skills, can we say anything about the inclusiveness of a country's skills distribution and its evolution over time? The 2012 Survey of Adult Skills, a product of the OECD Programme for the International Assessment of Adult Competencies (PIAAC), found that, on average across participating national and sub-national entities, $16.4 \%$ of 25-64 year-olds still have literacy skills below Level 2 although this average conceals wide variations between entities, as Figure 3 (vertical axis) demonstrates. In Italy, Spain and France over $20 \%$ of adults do not reach Level 2 for literacy skills.

\section{Figure 3. Share of 25-64 year-olds with low literacy skills, and average annual decrease across age groups (2012) Literacy proficiency in the Survey of Adult Skills}

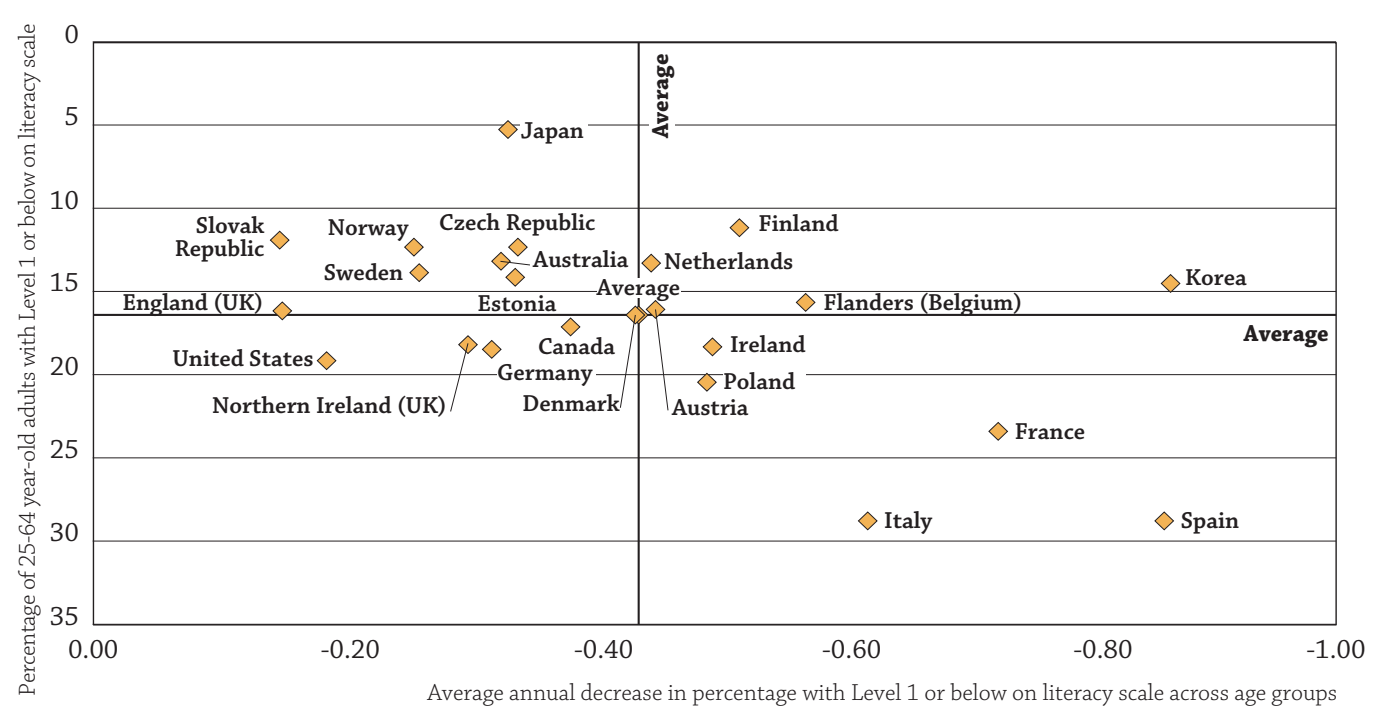

Source: OECD Online Education database, www.oecd.org/education/database.htm; OECD (2014), Education at a Glance 2014: OECD Indicators, http://dx.doi. org/10.1787/eag-2014-en.

Figure 3 also provides a measure of progress in reducing the share of adults with low literacy levels. Although there is no measure over time, looking at the difference in the share of 25-34 year-olds and 55-64 year-olds with low skills provides an estimate of the amount of progress made. However, in countries that have effective adult-learning systems through which older adults can improve their skills, such as Norway and Sweden, actual progress over time may be underestimated. Thus, this proxy should be interpreted with caution. All entities have seen the share of adults below Level 2 on the literacy scale fall by this measure, but in the Slovak Republic, England and the United States only very modest progress has been made. In contrast to the trend in educational attainment (see Figure 1), those entities with high percentages of adults with low literacy skills have also demonstrated the highest relative decreases.

\section{In all countries the skills distribution is skewed towards the bottom.}

Figure 4 shows the overall distribution of literacy skills among 25-64 year-olds as measured in the OECD Survey of Adult Skills (PIAAC). It shows that, in all national and sub-national entities participating in the survey, the distance between the median and the 10th percentile is greater than between the median and the 90th percentile. In all entities the distribution is skewed towards the bottom.

In the Slovak and Czech Republics, Japan, and Korea the overall size of the skills distribution is relatively small, suggesting a fairly inclusive distribution of literacy skills across the adult population. In contrast, in the United States, Canada, Finland 


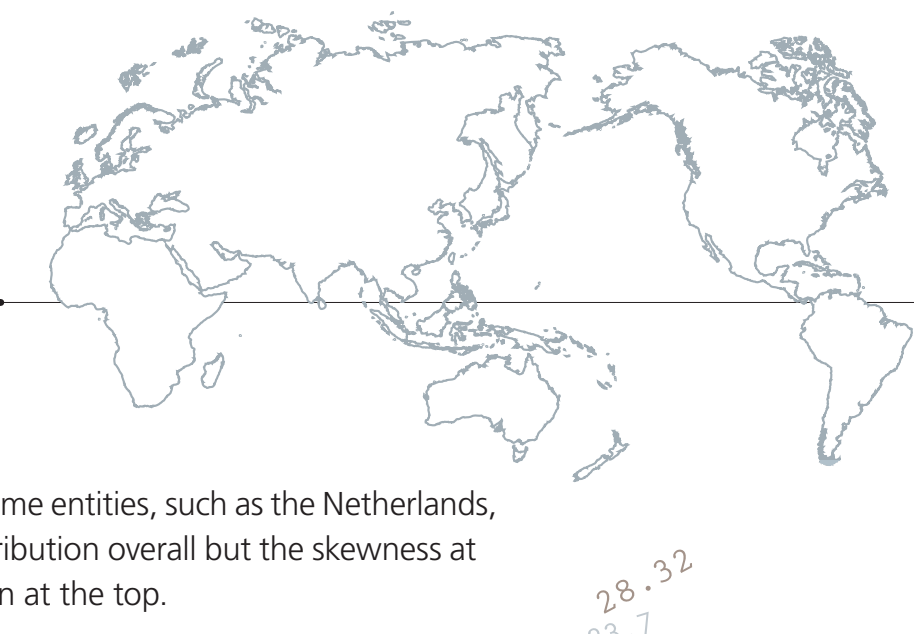

Figure 4. The distribution of literacy skills among 25-64 year-olds (2012) Literacy proficiency in the Survey of Adult Skills

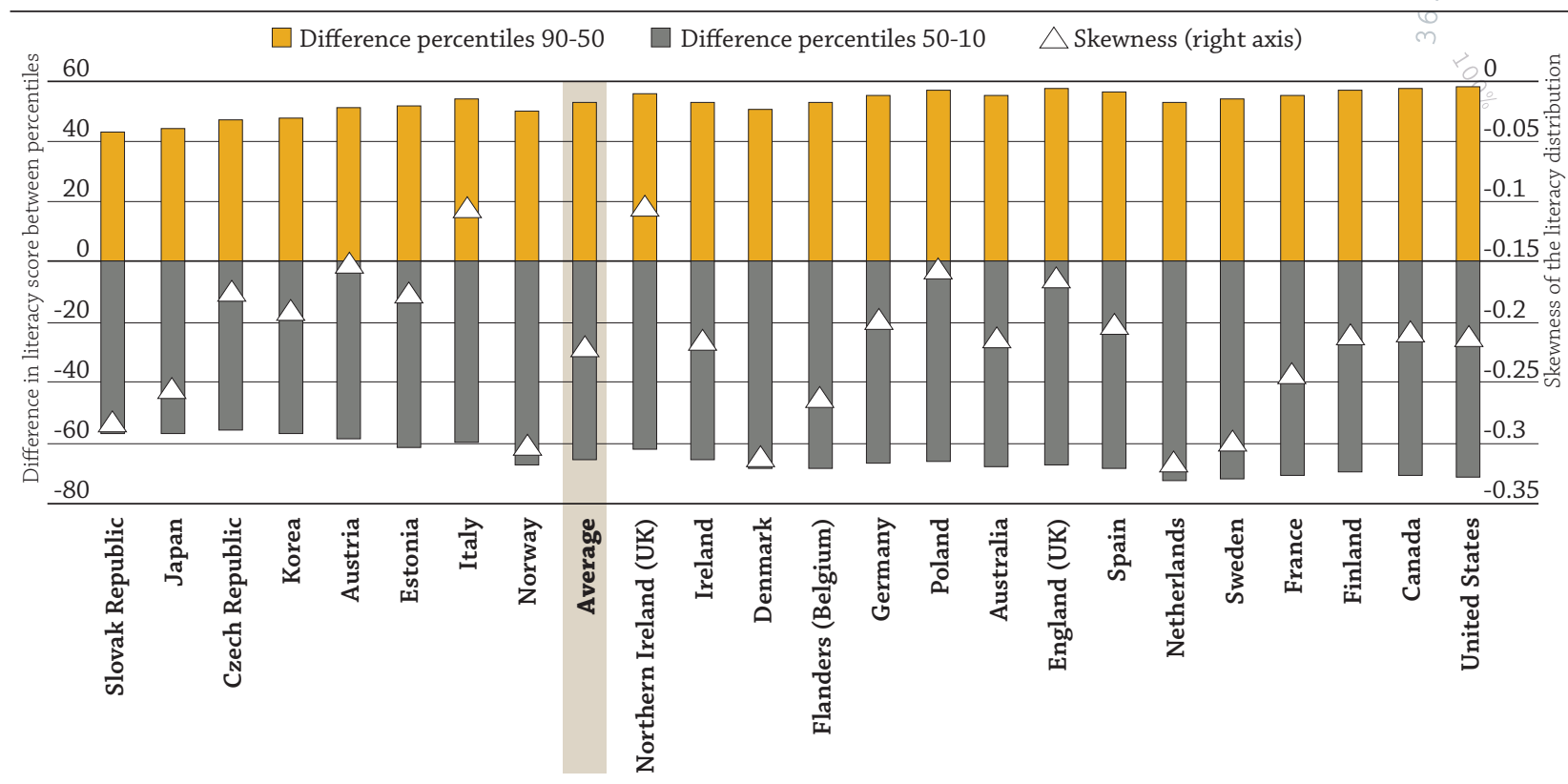

Note: Countries are ranked in increasing order of the distance between the 10th and 90th percentile.

Sources: Survey of Adult Skills (PIAAC) (2012) (database).

The bottom line: Not everyone has benefited from the increase in educational attainment and skills in the population in recent years. The shares of adults with low educational attainment and low skills remain significantly high, although the data suggest a fair amount of progress towards a more inclusive distribution of education and skills. Differences between countries are very significant, however, and some risk leaving parts of their population behind with enduring low levels of education and skills.

\section{For more information}

OECD (undated), Inclusive Growth project website, OECD, www.oecd.org/inclusive-growth/.

OECD (2015), Education at a Glance Interim Report: Update of Employment and Educational Attainment Indicators, OECD, Paris, www.oecd.org/edu/ eag-interim-report.htm.

OECD (2014), Education at a Glance 2014: OECD Indicators, OECD Publishing, Paris, http://dx.doi.org/10.1787/eag-2014-en.

OECD (2013), OECD Skills Outlook 2013: First Results from the Survey of Adult Skills, OECD Publishing, Paris, http://dx.doi.org/10.1787/9789264204256-en.

\section{Contact}

Dirk Van Damme (Dirk.Vandamme@oecd.org)

\section{Visit}

www.oecd.org/edu/eag.htm

Education Indicators in Focus (previous issues)

PISA in Focus

Teaching in Focus
Coming next month

What type of vocational education and training (VET) is needed to meet the needs of changing economies?

Photo credit: @ Ghislain \& Marie David de Lossy/Cultura/Getty Images

This paper is published under the responsibility of the Secretary-General of the OECD. The opinions expressed and arguments employed herein do not necessarily reflect the official views of OECD member countries.

This document and any map included herein are without prejudice to the status of or sovereignty over any territory, to the delimitation of international frontiers and boundaries and to the name of any territory, city or area.

The statistical data for Israel are supplied by and under the responsibility of the relevant Israeli authorities. The use of such data by the OECD is without prejudice to the status of the Golan Heights, East Jerusalem and Israeli settlements in the West Bank under the terms of international law. 